\title{
Applications and Limitations of Single- Phase Models to the Description of the Rapid Filling Pipe Problem
}

Jose G. Vasconcelos and Steven J. Wright

The study of the hydraulic behavior of stormwater sewers during intense rain events is motivated by operational problems associated with this rapid filling process they experience. As is well known, intense rain events may trigger the occurrence of pipe-filling bores, which causes flow regime transition between free-surface and pressurized flows and also expulsion of the air within the pipes. In some cases, these bores cause problems such as structural damages to the drainage system and geysering through manholes. Various approaches to promote the numerical simulation of the flow regime transition are available, and some of them incorporate the effects of the air phase within the pipes. In most cases, the modeling of the air phase dynamics is simplified, improving only the calculation of the bore speed changes due to the air pressurization. However, experimental investigations promoted by Vasconcelos and Wright (2004a) demonstrated that the effects of the air pressurization are not limited only to the bore propagation but also contribute to other changes in the flow behavior. In cases when the venting conditions are too limited, the single phase flow approach to modeling system behavior may be insufficient. This work aims to explore the applicability limits of single-phase numerical models for the rapid filling pipe problem using a simplified treatment for the air phase. The numeric code solves the SaintVenant equations with the Preissmann slot using a finite volume procedure able to capture shocks with minimum numerical diffusion. Air phase

Vasconcelos, J. and S.J. Wright. 2005. "Applications and Limitations of Single-Phase Models to the Description of the Rapid Filling Pipe Problem." Journal of Water Management Modeling R223-19. doi: 10.14796/JWMM.R223-19. (C) CHI 2005 www.chijournal.org ISSN: 2292-6062 (Formerly in Effective Modeling of Urban Water Systems. ISBN: 0-9736716-0-2) 
description assumes quasi-steady flow, allowing for the development of air pressure gradient within the system. The numerical results of the simulation are compared with available experimental data, and cases in which more complex flow features are developed are discussed. The comparison shows that the proposed model provides a generally accurate description of the flow behavior, and also is able to predict when its applicability would be compromised by the development of more complex flow phenomena.

\subsection{The Rapid Filling Pipe Problem}

The operational conditions of stormwater drainage systems may be drastically altered during intense rain events. These systems are usually designed to operate as open-channel structures but intense rain events may create conditions where the conveyance as open-channel is exceeded causing the development of full-pipe, pressurized flow. Provided that a conduit is long enough, it is possible that this flow regime transition will occur in the form of a moving hydraulic jump, or a bore, which divides the tunnel in two flow regions: ahead of the bore there is the free-surface flow, and prior to the bore pressurized flow. This condition is frequently referred as rapid filling pipe problem, and the interest for this subject comes from the many operational problems that may arise during these events.

These problems include the geysering from vertical shafts and structural damages resulting of waterhammer-like pressures (Guo and Song, 1990, 1991; Zhou et al., 2002).

The subject of flow regime transition has been studied by a several authors both numerically and experimentally. Pioneer works by Wiggert (1972), Cunge et al. (1980), Song et al. (1983), among others, provide different model approaches to the description of the problem. There are particular difficulties to model this problem arising from differences in the characteristics of freesurface and pressurized flow regimes. First, the celerity of free-surface flows can be between two to three orders of magnitude smaller than the correspondent one for pressurized flow. Second, while pressurized flow can occur with negative gage pressures, such is not possible in the free-surface flow regime. Third, with multiple inflow points, the possibility exists for multiple flow regime transitions to occur simultaneously. Finally, the calculation of the pressurization bore requires the conservation of mass and momentum across it, and the sharp discontinuity on the depth across the bore may pose difficulties in terms of the numerical scheme to be used (Glaister, 
1988). There are also model difficulties related to the presence of the air phase inside the tunnels.

One can generally classify the different numerical models to the rapid filling pipe problem in two basic groups: interface-tracking models and Preissmann slot based models. Interface-tracking models apply different sets of equations to the description of the pressurized and free-surface portions of the flow, requiring the computation of the pressurization front at each time step. Among the models using this concept, one includes the works by Wiggert (1972), Cardle and Song (1988), among others. One drawback of this type of models is the requirement of computing the pressurization fronts, which may be relatively difficult in complex configurations of tunnels, especially if multiple fronts can develop.

This difficulty is not shared by models using the Preissmann slot concept since they utilize the open-channel mass and momentum balance equations throughout the domain. These types of models introduce a hypothetical, narrow slot at the top of the sewers, emulating the surcharging conditions of the sewers, while keeping the characteristics of a free-surface flow. Examples of these models are provided by Garcia-Navarro et al. (1994) and Capart et al. (1997), among others. The slot width must be chosen so the resulting celerity of the pipe with the slot matches the one of the pressurized portion of the flow (Equation 19.1):

$$
c=V \pm \sqrt{\frac{g A}{T}}
$$

where:

$$
\begin{aligned}
c & =\text { the celerity } \\
V & =\text { water flow velocity } \\
g & =\text { gravity acceleration, } \\
A & =\text { cross sectional area of conduit and } \\
T & =\text { slot width. }
\end{aligned}
$$

There are, however, some difficulties with the application of the Preissmann slot concept related to the transmission of low pressure waves. If the piezometric pressure drops below the pipe crown, Preissmann slot models would respond by decreasing the flow depth below the pipe crown at a given location. However, that is not realistic unless there is a ventilation source at this particular point. Another difficulty of the Preissmann slot models are related to the description of the depth discontinuity at the pressurization front. Standard linear, finite-difference schemes would result either in bore predictions with excessive numerical diffusion or with unrealistic numerical 
oscillations at the vicinity of the discontinuity, according to the Godunov theorem. The solution to this problem is to apply nonlinear schemes to this problem, and a list of different alternatives is presented by Macchione and Morelli (2003).

In any numerical approach, there may be additional issues related to the presence of the air phase in the tunnels during the rapid filling pipe event. The following section will discuss the changes in the flow dynamics caused by air phase flow.

\subsection{Air Phase Effects On The Rapid Filling Pipe Problem}

Air phase is expelled from the sewers during the rapid filling pipe event through any available venting point. Provided that the amount of ventilation is adequate within the conduit, air phase pressurization will be minimal, and the correspondent changes in the system dynamics caused by this pressurization will be negligible. But, if for any reason the ventilation is not adequate, air phase pressure can change the flow dynamics significantly, according to experimental research promoted by Zhou et al. (2002) and Vasconcelos and Wright (2004a).

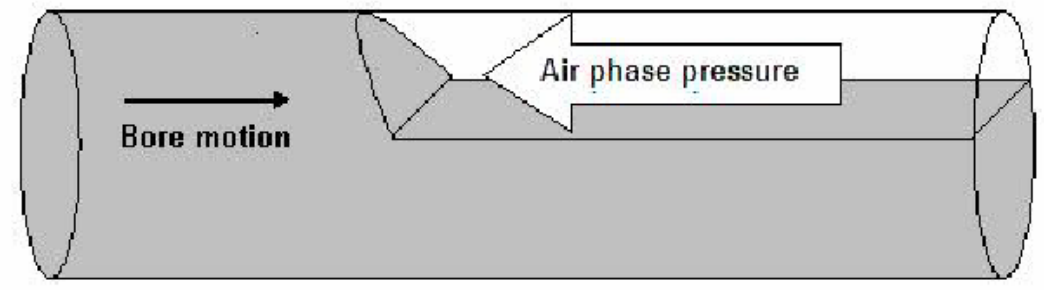

Figure 19.1 "Air cushioning" effect on the pipe filling bore

The immediate consequence of the air pressurization would be related to the expected reduction on the bore speed due to an "air cushioning" effect, as illustrated in Figure 19.1. Previous studies (Martin, 1976; Cabrera et al., 1990) addressed the issue of the rapid filling of an upward-sloped pipeline where no ventilation was allowed, with the objective of studying the pressurization of the air pocket entrapped at the end of the pipeline. However in stormwater systems some degree of ventilation is expected, since manholes constitute venting points. Zhou et al. (2002) studied the rapid filling of a 
horizontal pipe, and measured the system behavior for different ventilation scenarios. The authors confirmed that in poorly ventilated systems the pressurization front would be retarded by an air-cushion. These works assume that behind the pressurization front there is only water, while ahead of the front there is only air, yet this condition is not expected in near horizontal pipelines.

Geometry particularities may be one cause of the reduction of the ventilation area in storm systems, such as in cases when the pipe is downward sloped or when there are excessive local losses in manholes. Vasconcelos and Wright (2004a) promoted a series of experiments that aimed to determine the conditions for which the air phase pressurization would be significant in downward-sloped pipelines, as represented in Figure 19.2. The authors noticed various types of interactions between air and water phases during the motion of a pipe-filling bore:

1. When the initial water level of the system is low, then ventilation will be adequate and no signs of air pressurization will be noticed;

2. As the initial water level increases above some level, then it will be possible to notice the motion of the water in the free-surface portion of the system towards the surge tank. That flow feature was referred as "pre-bore motion", as seen in Figure 19.2:

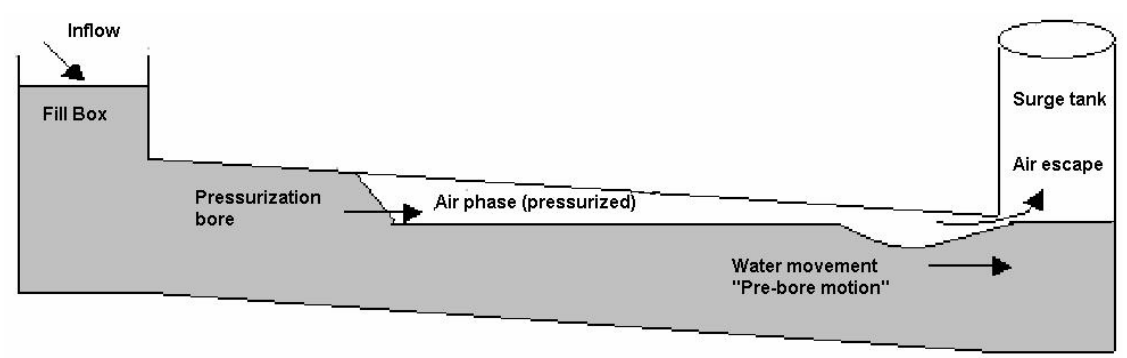

Figure 19.2 Schematics of the occurrence of the "pre-bore motion" feature. Vertical scale is exaggerated

3. Further increase of the initial water level will lead to a condition when the pipe-filling bore will experience an upstream intrusion of air at the top (see Figure 19.3). Following the occurrence of this intrusion, the bore will resume the movement towards the surge tank, but not closing the entire cross section. The air pocket will move upstream in a shape resembling a gravity current. That feature was referred as "interface breakdown": 


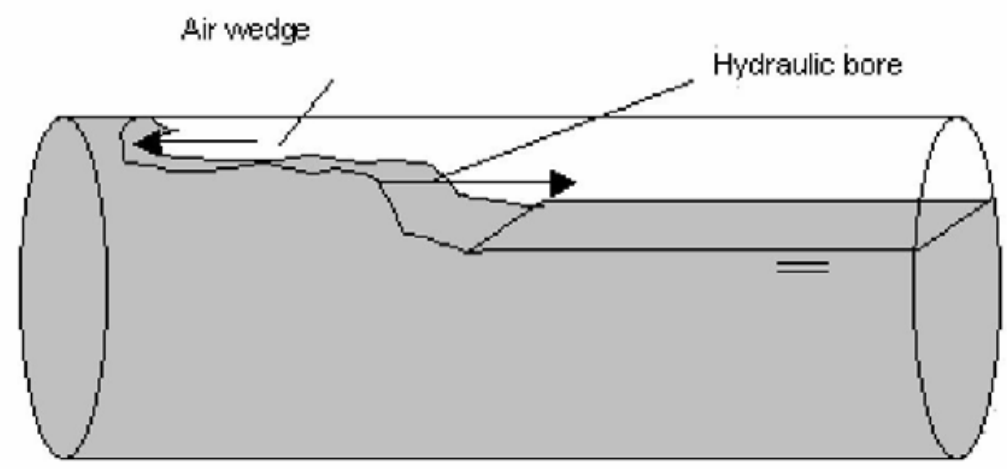

Figure 19.3 Schematics of the occurrence of the "interface breakdown" feature

4. If initial water level is increased even more, the formation of a pipefilling bore does not occur, but rather an undular front propagates towards downstream.

Thus, if ventilation is not adequate the changes on the system dynamics will not be restricted to the pressurization bore motion but instead the whole system response may be altered. Of particular interest is the possibility of air pocket generation, since these pockets may cause geysering through manholes and waterhammer-like pressures if they are evacuated rapidly through any venting point. Consequently, the prediction of such events by numerical models is very much desirable. The next section addresses model approaches that include the air phase in the calculations.

\subsection{Including Air Phase in Model Predictions}

As previously mentioned, there are some difficulties in incorporating the air phase in a model describing the rapid filling pipe problem. The first one is to choose between a single-phase model approach, in which only the mass and momentum equations for the water phase are used, or a two-phase flow model, in which mass and momentum equations for both phases are used. The second is to determine which numerical scheme is to be used in the solution of the problem. Finally it is to determine which interactions between phases can be handled by the model. 
Single-phase models dealing with the air phase pressure are comparatively simpler to create because they require a smaller number of equations to be solved. On the other hand, the ability of single-phase models to describe the possible interactions between the two phases during a rapid filling pipe event is more limited. Examples of single-phase models are provided by Hamam and McCorquodale (1982), Li and McCorquodale (1999) and Zhou et al. (2002). In these models, the velocity of the pressurization bore is affected by the air phase pressure, but the air pressurization does not affect directly the water phase underneath it. As a consequence, flow features such as the "prebore motion" cannot be described. However, this problem can be solved if the model approach incorporates air phase pressure in the momentum balance of the water phase. Examples of such models were presented by Nguyen (1999) and Vasconcelos and Wright (2004b), both using the Preissmann slot concept.

Probably, the greatest limitation of single-phase approaches is the number of simplifications required for the computation of the air phase behavior. For example, it may be assumed that, regardless of the venting conditions, the pressurization bore will push air outside the system, thus neglecting the possibility of "interface breakdown". Improvements in single phase models, such as the one proposed by $\mathrm{Li}$ and McCorquodale (1999), expand the applicability of the models by allowing for Kelvin-Helmholtz type of instabilities to develop. But in this model the shear forces between the phases are not directly incorporated, and the instability occurrence is conditioned on certain relative velocity between the two phases. On the other hand, Preissmann slot models that incorporate air pressure in the water momentum equations won't be able to handle adequately air pockets formed by flow instabilities or by the occurrence of the "interface breakdown".

Although rapid filling pipe problems are two-phase phenomena per se, there are still some challenges to be addressed before two-phase flow formulations are fully applicable to the problem. For instance, a model approach that solves the problem as a two-phase flow problem was proposed by Arai and Yamamoto (2003), but according to the authors their model is not able to simulate the moving bore. That may be due to the numerical procedure chosen by the authors (the 4-point Preissmann implicit scheme), which has a diffusive-like characteristic. In any case, the shock-capturing capability is one important feature that should be present in a model to this type of problem.

The solution of the four partial differential equations that represents mass and momentum balance for each phase requires an adequate numerical procedure due to the discontinuous nature of the flow. The advance of the pressurization bore constitutes a type of Riemann initial value problem, and exact Riemann solvers aren't available to this set of equations. Approximate 
Riemann solvers, such as the one proposed by Roe (1981), require the calculation of the set of eigenvalues and eigenvectors of the Jacobian matrix correspondent to the set of four pde's, which are difficult to obtain. Our research is currently trying to determine an accurate approach that can address these issues and construct a two-phase code able to describe the advance of the pressurization bore accurately.

In other types of quasi-horizontal, two-phase flow problems, such as oil pipeline flows, the use of transient two-phase flow codes is a common practice, such as the models proposed by Barnea and Taitel (1993), DeHenau and Raithby (1995) and Issa and Kempf (2003). However there are no references on how discontinuities such as bores would be handled, probably because this is not a significant issue in those types of flows. Moreover, time steps in these type of models may yield relatively high Courant numbers for the pressurized portions of the flow, which may compromise the accuracy of the solution in these zones.

Summarizing, to the present literature there is no satisfactory general way to model the rapid filling pipe problem. Existing single phase models are adequate to solve only part of all possible interactions that water and air phases may have, and the existent two-phase codes are yet not adapted to handle the discontinuous nature of the problem. This Chapter aims to explore the limits in which single phase models would be applicable to solve the rapid filling pipe problem with a reasonable degree of precision.

\subsection{Proposed Model}

The motivation to construct this model using a single-phase approach is the relative simplicity of this alternative and also the particular characteristics of the problem, which allows for important simplifications with regards to the air phase modeling. The following sub-sections discuss details of the problem modeling.

\subsubsection{Water Phase Modeling}

The modeling of the water phase follows the general approach to solve the Saint-Venant equations using the Preissmann slot, which is discussed in Garcia-Navarro et al. (1994) and others. For modeling purposes, a 1st order approach would provide accuracy compatible to the simplified treatment given to the air phase flow. However, unlike the approach followed in 
Vasconcelos and Wright (2004b), the use of linear schemes was avoided, to escape the undesired consequences predicted in Godunov's theorem. Thus, Roe 1st-order upwind scheme was applied with a finite volume method. The Saint-Venant equations for prismatic channels in conservative, vectorized form that incorporates the air phase effects is the following:

$\frac{\partial \vec{U}}{\partial t}+\frac{\partial F(\vec{U})}{\partial x}=S(\vec{U})$

in which, for locations without air phase

$\vec{U}=\left[\begin{array}{l}A \\ Q\end{array}\right] \quad F(\vec{U})=\left[\begin{array}{c}Q \\ \frac{Q^{2}}{A}+g I\end{array}\right] \quad S(\vec{U})=\left[\begin{array}{c}0 \\ g A\left(S_{o}-S_{f}\right)\end{array}\right]$

and for locations with air phase

$\vec{U}=\left[\begin{array}{l}A \\ Q\end{array}\right] \quad F(\vec{U})=\left[\begin{array}{c}Q \\ \frac{Q^{2}}{A}+g I+g A_{\text {pipe }} H_{\text {air }}\end{array}\right] \quad S(\vec{U})=\left[\begin{array}{c}0 \\ g A\left(S_{o}-S_{f}\right)+\frac{1}{\rho_{w}} F_{i} B\end{array}\right]$

where:

$$
\begin{aligned}
A & =\text { cross sectional area of water, } \\
A_{\text {pipe }} & =\text { the cross sectional area of the pipe } \\
Q & =\text { the water flow rate, } \\
I & =\text { the } 1 \text { st moment of the cross sectional area about the }
\end{aligned}
$$

free surface,

$$
\begin{aligned}
H_{\text {air }} & =\text { the air phase pressure head } \\
S_{o} & =\text { the bed slope, } \\
S_{f} & =\text { the energy slope (given by Manning equation) } \\
\rho_{\mathrm{w}} & =\text { the water density (assumed constant) } \\
B & =\text { the free surface width, } \\
F_{i} & =\text { the shear forces between the phases. }
\end{aligned}
$$

To compute the updated values of $A$ and $Q$ using Roe's scheme, one need to solve the Riemann problem approximately in each one of the finite cells interfaces. That requires the calculation of the fluxes on each side of the interfaces as well the contribution of the wave that intersects the control volume. Following Macchione and Morelli (2003), the updated value for the quantities $U$ are provided by: 


$$
\begin{aligned}
U_{i}^{n+1}=U_{i}^{n} & -\frac{\Delta t}{2 \Delta x}\left[\left(F_{i+1}^{n}+F_{i}^{n}\right)-\sum_{j}\left|\overline{\lambda^{(j)}}\right|\left(\delta w^{(j)}\right)_{i+1 / 2} \bar{r}_{i+1 / 2}^{(j)}\right] \\
+ & \frac{\Delta t}{2 \Delta x}\left[\left(F_{i-1}^{n}+F_{i}^{n}\right)-\sum_{j}\left|\overline{\lambda^{(j)}}\right|\left(\delta w^{(j)}\right)_{i-1 / 2} \bar{r}_{i-1 / 2}^{(j)}\right]+\Delta t S_{i}^{n}
\end{aligned}
$$

In the above equation, $n$ is the time index. The values of the approximate values of the eigenvalues $\lambda^{(j)}$ and the correspondent eigenvectors $\boldsymbol{r}^{(j)}$ for $A$ and $Q$ across the interface require first the computation of the so-called Roe averages across each one of the interfaces $(i, i+1)$.

$$
\begin{gathered}
\bar{A}_{i+1 / 2}=\sqrt{A_{i} A_{i+1 / 2}} \\
\bar{Q}_{i+1 / 2}=\frac{\sqrt{A_{i}} Q_{i+1}+\sqrt{A_{i+1}} Q_{i}}{\sqrt{A_{i}}+\sqrt{A_{i+1}}} \\
\bar{c}_{i+1 / 2}=\sqrt{g \frac{I_{i+1}-I_{i}}{A_{i+1}-A_{i}}} \quad \text { if } A_{i} \neq A_{i+1} \\
\bar{c}_{i+1 / 2}=\sqrt{\frac{\frac{1}{2} g\left(A_{i+1}+A_{i}\right)}{\frac{1}{2}\left(B_{i+1}+B_{i}\right)}} \quad \text { if } A_{i}=A_{i+1}
\end{gathered}
$$

where $B$ is the width of the free surface.

With these values calculated, we now obtain the approximate eigenvalues and eigenvectors across interfaces $(i, i+1)$ with the equations: 


$$
\begin{aligned}
& \overline{\lambda_{1}}=\frac{\bar{Q}}{\bar{A}}+\bar{c} \\
& \overline{\lambda_{2}}=\frac{\bar{Q}}{\bar{A}}-\bar{c} \\
& \bar{r}^{(1)}=\frac{1}{2 \bar{c}}\left[\begin{array}{ll}
1 & \bar{\lambda}_{1}
\end{array}\right]^{T} \\
& \bar{r}^{(2)}=\frac{1}{2 \bar{c}}\left[\begin{array}{ll}
1 & \bar{\lambda}_{2}
\end{array}\right]^{T}
\end{aligned}
$$

Finally, the strength of the wave crossing the cell, measured in terms of the variations $\delta_{\mathrm{w}}$ at the interface, can be obtained with the equations:

$$
\delta w^{(1)(2)}= \pm\left[\left(Q_{i+1}-Q_{i}\right)+\left(-\frac{\bar{Q}_{i+1 / 2}}{\bar{A}_{i+1 / 2}} \pm \bar{c}_{i+1 / 2}\right)\left(A_{i+1}-A_{i}\right)\right]
$$

This set of equations must be solved for all internal finite volume cells within each time step. The boundary conditions are treated in a very similar manner as described by Vasconcelos and Wright (2004b). Basically, the system boundaries are comprised of an inflow box at the upstream end and a surge tank at the downstream end. At the upstream end the unknowns are the discharge entering the 1st cell, the flow area at the 1st cell and the water level on the fill box. There are three equations available: the C- characteristic equation, obtained with data from cells 1 and 2 from the previous time step; the energy equation between the fill box and the 1st cell; and the continuity equation. Those set of equations need to be solve iteratively until convergence. Similarly, at the downstream end, the unknowns are the discharge and flow area at the last cell, and the water level at the surge tank. The equations used now to solve are the $y$-momentum equation in the surge tank (thus accounting for the inertia in the surge tank), $\mathrm{C}+$ characteristic equation and continuity. An iterative process is also used here to achieve convergence. 


\subsubsection{Air phase modeling}

The wave celerity in the air phase is much faster than the speed of the superficial disturbances in the free surface region or than the speed of the pressurization bore. Thus, one may assume air phase flow as quasi-steady since there is enough time for several reflections of the air pressure transients within the discretized domain for each discrete advance of the pressurization bore. That assumption allows for an important simplification of the mass balance equation for the air phase (Equation 19.7):

$$
\frac{d M}{d t}=0
$$

in which $M$ is the air mass rate of flow and $t$ is time.

As a result, the continuity equation for the air phase written in the discretized domain becomes:

where:

$$
\rho_{i} A_{i} V_{i}=\rho_{i-1} A_{i-1} V_{i-1}
$$

$$
\begin{aligned}
i & =\text { the grid cell index } \\
\rho & =\text { the air density, } \\
A & =\text { the cross sectional area of the air phase and } \\
V & =\text { the air phase velocity. }
\end{aligned}
$$

Further simplifications are introduced in the momentum equation. Initially, if the flow is quasi-steady, then the temporal derivative disappears from the equation. Because the problem deals with quasi-horizontal conduits, the gravity terms are dropped from the equation as well. The only terms left are related to the pressure gradient and frictional forces. Following the development provided in Wylie and Streeter (1993) for steady state equations in gas pipelines, we have the equation that relates the air pressure between two points in the pipeline:

$$
p_{i}^{2}=p_{i-1}^{2}-\frac{f c_{a}^{2} M^{2}}{D A^{2}} \Delta x
$$

where: 


$$
\begin{aligned}
p & =\text { the air pressure } \\
f & =\text { the friction factor (assumed constant) } \\
c_{a} & =\text { acoustic wavespeed in the air } \\
D & =\text { the effective diameter, and } \\
\Delta x & =\text { the distance between grid cells centerpoints. }
\end{aligned}
$$

Finally, to achieve closure of the equations that describe the air phase pressure, we need to define a relationship between air density and pressure. This model assumes that air phase will undergo an isothermal compression, so

$$
\sqrt{\frac{p}{\rho}}=c_{a}=\text { const. }
$$

The boundary conditions for the air phase are very much similar to the one presented in Vasconcelos and Wright (2004b). At each time step, the net volume of water that has entered the tunnel equals the volume of air that has left the system. Because air density changes between each time step, a simple orifice equation is used to relate the air discharge with the pressure head at the discharge point, based in Zhou et al. (2002):

$$
Q_{\text {air }}=C_{d} A_{\text {orif }} \sqrt{2 g \frac{\rho_{\text {water }}}{\rho_{\text {air }}} H_{\text {air }}}
$$

where:

$$
\begin{aligned}
Q_{\text {air }} & =\text { the volumetric flow rate of air, } \\
C_{d} & =\text { the orifice } \mathrm{d}=\text { charge coefficient, } \\
A_{\text {orif }} & =\text { the available ventilation area, } \\
g & =\text { gravity, } \\
\rho_{\text {air }} & =\text { the density of the air phase at the } \mathrm{d}=\text { charge point } \\
H_{\text {air }} & =\text { the air phase pressure head. }
\end{aligned}
$$

The calculation follows this procedure: given the net water flow entering the tunnel $Q_{w}$, the value for $Q_{a i r}$ is obtained by setting $Q_{a i r}=Q_{w}$. At the discharge point, the value for $H_{\text {air }}$ is obtained using Equation 19.11, allowing for the calculation of the new values for $p$ and $\rho_{\text {air }}$ at the discharge point. The air phase mass flow $M$ (assumed steady) is obtained by setting $M=Q_{\text {air }} \rho_{\text {air }}$ at the discharge point. To determine the air phase density, pressure and velocity for 
all cells upstream from the discharge point, Equations 19.8, 19.9 and 19.10 are used. Calculations stop in the section where the pressurization bore is located.

\subsection{Model Validation}

The predictions of the proposed single-phase model were compared to experimental data obtained in a physical model comprising a $14.3 \mathrm{~m}$ long, 9.4 $\mathrm{cm}$ diameter acrylic pipeline. This model was used in previous investigations on the conditions in which large surges would develop upon sudden flow initiation (Wright et al., 2003).

At the upstream end of this tunnel is a fill box, with cross sectional dimensions of $0.25 \mathrm{~m} \mathrm{x} 0.25 \mathrm{~m}$, and spill level of $0.216 \mathrm{~m}$ above the level of the pipe crown. Starting with the system in complete rest, flow is suddenly introduced into the tunnel through the fill box by means of a two-way valve. To simplify the study in terms of air phase ventilation, the introduced flow rate and initial depth must be such that a pipe-filling bore forms immediately, blocking air escape through the fill box. At the other extreme of the tunnel, there is the surge tank (or riser), where oscillations are expected as the bore arrives at that location.
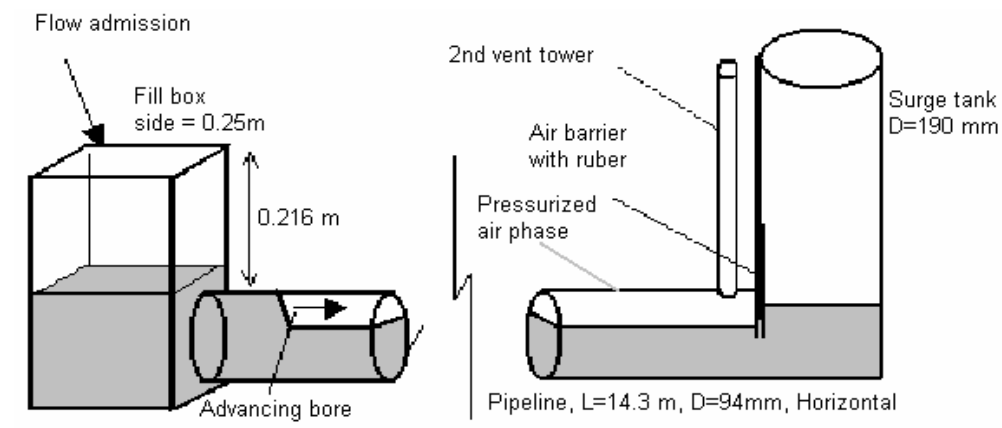

Figure 19.4 Scheme of the physical model used on for model comparison

Changes were made to this end of the model to simplify the ventilation conditions. A gate, which projected below the initial water depth, was installed at the end of the pipeline to prevent air escape through the surge 
tank. The only vent available is provided by a venting tower installed close to the downstream end of the pipeline, on the top of which different rounded nozzles are placed. By changing the diameter of these nozzles it is possible to effectively control the degree of ventilation allowed in the system. The representation of the physical model is presented in Figure 19.4.

Because the main goal of this work is to determine the limits of applications of single phase model approaches to the description of the rapid filling process, it was decided to study two ventilation conditions:

- "Moderate" ventilation - $3 / 8$ " rounded nozzle at the vent tower: In these conditions the experimental runs indicated the occurrence of "pre-bore motion" features only;

- "Poor" ventilation - 1/4" rounded nozzle at the vent tower: In these conditions there was the occurrence of "pre-bore motion" and in some cases of "interface breakdown", or IBD. If in a given experimental run IBD occurred, then there was an air pocket entrapped behind the advancing bore.

In order to promote a systematic approach to study these two ventilation conditions, and also to assure the formation of a pipe-filling bore upon flow initiation, eight different experimental settings were tested, each with three repetitions. The experimental variables are displayed in Table 19.1:

TABLE 19.1 Experimental variables and respective range tested for the model validation

\begin{tabular}{ll}
\hline Experiment variable & Range tested \\
\hline Initial water depth & $7.1 \mathrm{~cm}$ and $7.5 \mathrm{~cm}$ \\
Flow rate & $3.1 \mathrm{~L} / \mathrm{s}$ and $3.9 \mathrm{~L} / \mathrm{s}$ \\
Ventilation nozzles & $D_{\text {orif }}=3 / 8 "(9.53 \mathrm{~mm})$ and $\mathrm{D}_{\text {orif }}=1 / 4 "(6.35 \mathrm{~mm})$ \\
\hline
\end{tabular}

For each experimental run, the following data was collected (distances measured from upstream end):

- Water pressure at $9.6 \mathrm{~m}$ : Measured with piezo-resistive pressure transducer (1 PSIg), manufactured by ENDEVCO, located at the bottom of the pipe;

- Water flow velocity at $9.6 \mathrm{~m}$ : Measured with an Acoustic Doppler Velocimeter (ADV), manufactured by SONTEK

- Air pressure at $14.1 \mathrm{~m}$ : Measured with piezo-resistive pressure transducer (1 PSIg), manufactured by ENDEVCO, located at the top of the pipe. This device was primarily utilized to measure air phase pressure; 
- Water pressure at $14.1 \mathrm{~m}$ : Measured with piezo-resistive pressure transducer (1 PSIg), manufactured by ENDEVCO, located at the bottom of the pipe;

- Water depth at $14.1 \mathrm{~m}$ : measured with a digital camera, with 30 frames per second speed.

The following section presents the comparison between the experimental results and the respective numerical predictions for all the conditions represented in Table 19.1.

\subsection{Results Comparison}

\subsection{1 "Moderate" Ventilation Case}

In this section a comparison was made between the model and the experimental results when the $3 / 8$ inch $(10 \mathrm{~mm})$ nozzle was used as ventilation. Initially the results of the simulated velocity at the $9.6 \mathrm{~m}$ station will be compared, followed by the pressure data at the same location. Then the pressure and water depth data at the $14.1 \mathrm{~m}$ station will be discussed.

\section{Water flow velocity at $9.6 \mathrm{~m}$ station}

The results of the experimental measurements of the velocity at the $9.6 \mathrm{~m}$ station are compared with the corresponding predictions from the proposed model and displayed in Figure 19.5. In all plots, the bore arrival is signaled by a sharp increase in the velocity. The bore arrival time is smaller for higher initial water depths and inflow rates, as expected. Good agreement is observed between the model and experiments in terms of the arrival time of the pressurization bore, as well as the predicted velocity behind the bore. But one may also notice that there is a small increase in the velocity both in the experiments and in the numerical predictions prior to the bore arrival. This is related to the occurrence of the "pre-bore motion" due to the air pressure gradient within the tunnel. The subsequent oscillations in the velocity reflect the oscillations in the water level in the surge tank, resulting from the arrival of the pressurization bore at that location.

\section{Water pressure at $9.6 \mathrm{~m}$ station}

The results of the experimental measurements pressure head variation of the water at the $9.6 \mathrm{~m}$ station are compared with the corresponding data from the 
proposed model and displayed in Figure 19.6. The model predicts accurately the immediate increase of the pressure head resulting from the air pressurization. One may also notice that the model is very good in predicting the passage of the pressurization bore at the station, which is marked by a sudden jump in the pressure head occurring between $T=5 \mathrm{~s}$ and $T=10 \mathrm{~s}$.



Figure 19.5 Comparison of velocity at the $9.6 \mathrm{~m}$ between proposed model and the experimental runs - "Moderate" ventilation case.

Some of the limitations of the proposed model become apparent after the bore reaches the surge tank, since there are high-frequency numerical oscillations in the results, which are not observed in the experimental data. After a careful analysis, it was detected that this behavior is originated in part by the form in 
which the calculation at the downstream boundary condition is promoted. But these results are worsened by the limitations of the Preissmann slot concept with regards to the transmission of low pressure waves.

As explained, if a low pressure wave travels is the system carrying a pressure smaller than the pipe diameter, this will cause the drop of the depth below the level of the pipe crown. This unrealistic behavior contributes to this inaccuracy.
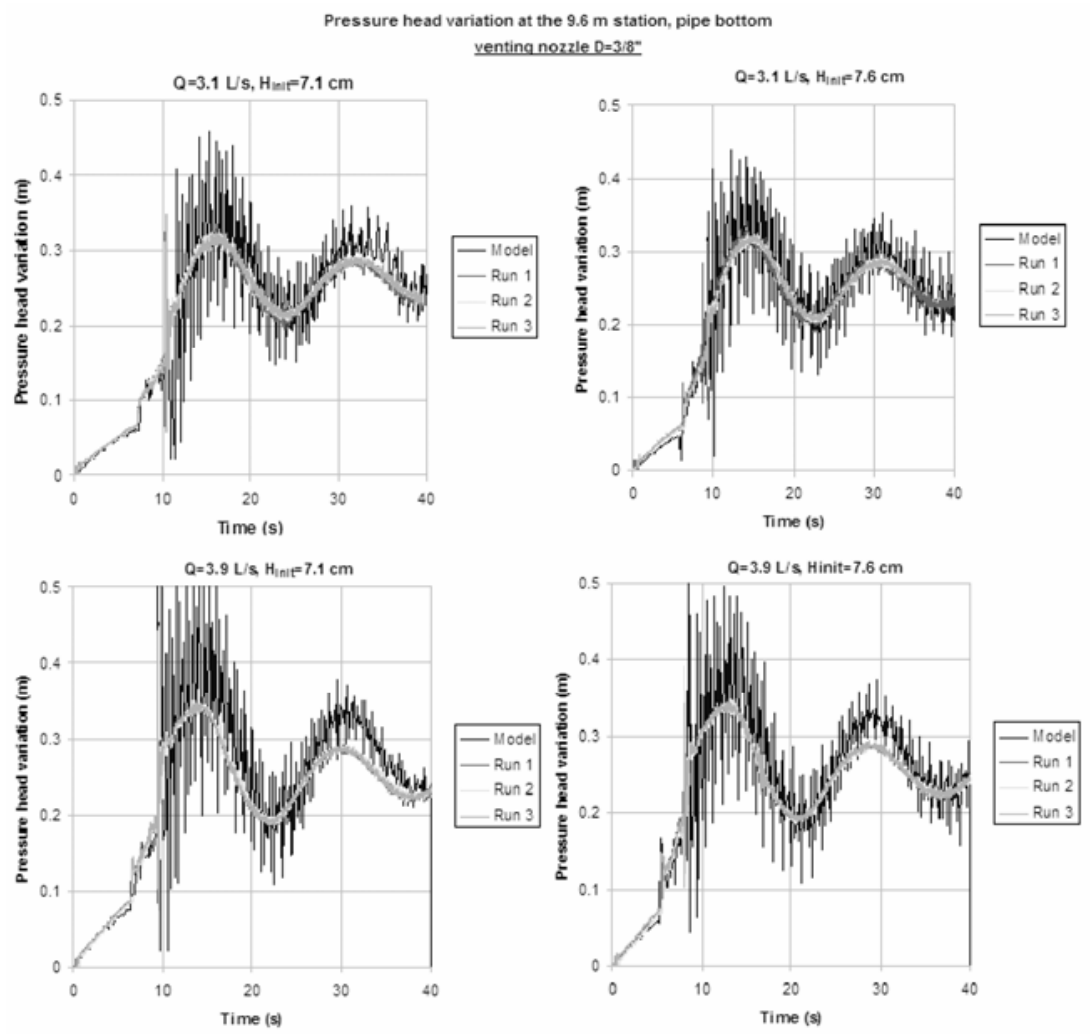

Figure 19.6 Comparison of water phase pressure head variation at the $9.6 \mathrm{~m}$ between proposed model and the experimental runs - "Moderate" ventilation case.

However, after "averaging" between the oscillations, the predicted value for the pressure head variation is reasonably close to the experiments. There is in 
general an over-prediction of the values, which is more pronounced for the higher inflow rates, which is around $15 \%$.
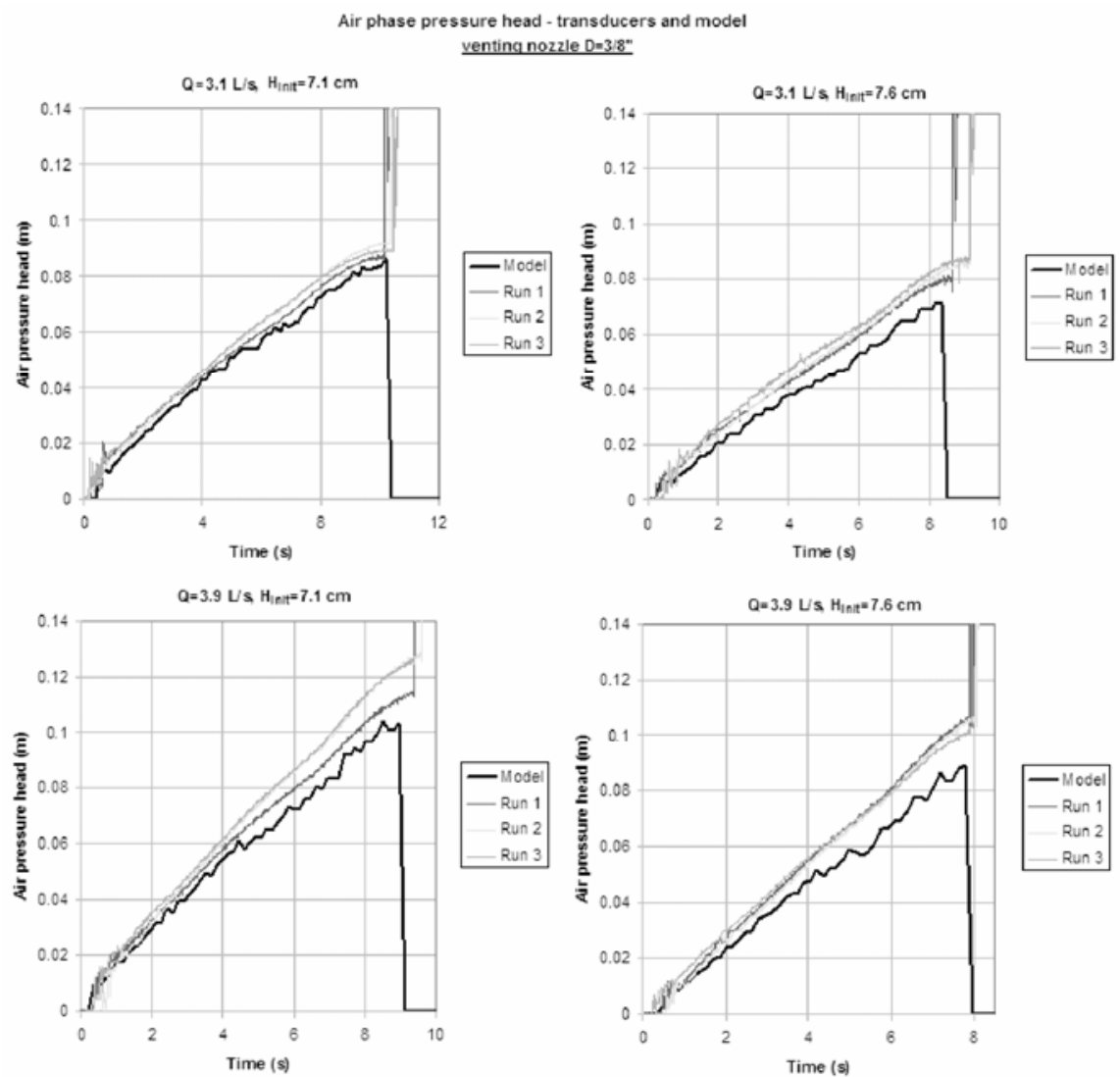

Figure 19.7 Comparison of air phase pressure head between proposed model and the experimental runs - "Moderate" ventilation case

\section{Air pressure at $14.1 \mathrm{~m}$ station}

The results of the pressure transducer located at the top of the pipe at the 14.1 $\mathrm{m}$ station, which gages only air phase pressure until the arrival of the bore, were compared with the correspondent model predictions. The plots are displayed in Figure 19.7. In general, the model was able to predict with reasonable accuracy the variation of the air pressure with time. There is some 
under-prediction of the results, particularly for the runs with higher initial water depth, but this difference usually is on the order of $10 \%$. Some oscillation occurred in the numerical results, with no clear explanation. It is probable that they are related to the simplified treatment given for the air phase modeling. One may speculate that if a mathematical model that conserves the air phase was applied instead, these oscillations would reduce or disappear.


Figure 19.8 Comparison of water phase pressure head variation at the $14.1 \mathrm{~m}$ between proposed model and the experimental runs - "Moderate" ventilation case

\section{Water pressure at $14.1 \mathrm{~m}$ station}

The comparison for the pressure head at the $14.1 \mathrm{~m}$ station is very much similar to the one made for the $9.6 \mathrm{~m}$ station. There is a initial period of pressure increase due to air phase pressurization that is well described by the proposed model. Upon bore arrival, there are the pressure increases as the 
surge tank water level increases, but also there are the same type of highfrequency oscillations which have no physical basis. In this case, however, the magnitudes of these oscillations are smaller, and this is probably caused by the proximity of this point to the surge tank. Also there is some overprediction of the so-called average pressure, mainly in the higher inflow conditions.

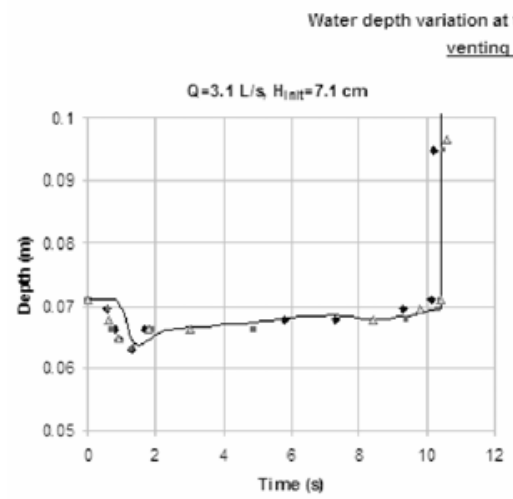

$14.1 \mathrm{~m}$ station pipe bottom

ting nozzle $D=3 / 8^{*}$



- Run 1 - Run 2 a Run 3 - Model

+ Run 1 - Run $2 \Delta$ Run 3 - Model
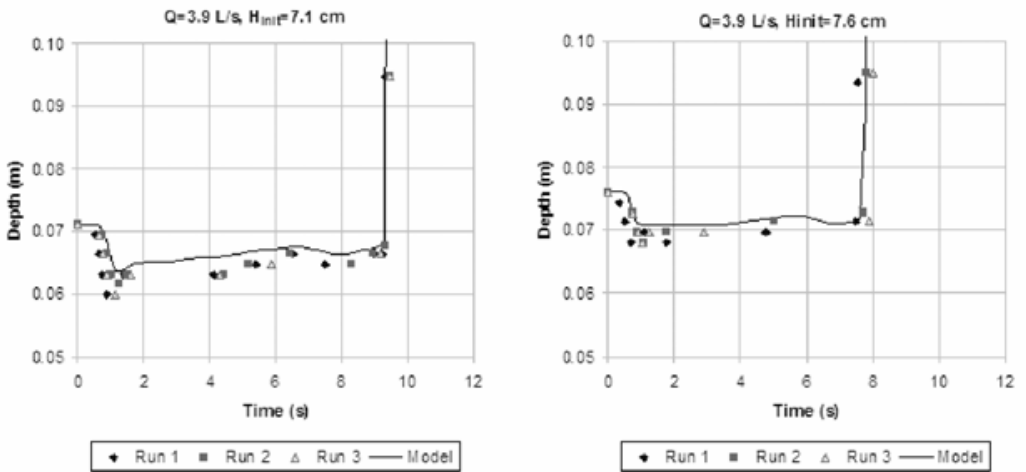

Figure 19.9 Comparison of water depth variation at the $14.1 \mathrm{~m}$ between proposed model and the experimental runs - "Moderate" ventilation case

Water depth at $14.1 \mathrm{~m}$ station

The comparison between the depth changes captured with the digital camera in the three runs and the model predictions are displayed in Figure 19.9. The 
predictions are generally very good. The behavior of the depth changes was adequately captured including the instants when the "pre-bore motion" feature occurs and when the pressurization bore arrives. Among the different experimental runs there are few discrepancies which are related to small ripples that are observed on the water surface during the rapid filling events. The plots were drawn using the same scale so to illustrate the different arrival times of the pressurization bore in each of the conditions tested.

\subsection{2. "Poor" Ventilation Case}

In this section the comparison between the model and the experimental results is discussed when the $1 / 4$ inch $(6 \mathrm{~mm})$ nozzle was used as ventilation. Both the experimental runs and the numerical predictions indicate that this change in nozzle diameter has increased significantly the air phase pressure, roughly doubling it. The results are generally not as good as the correspondent ones in the "Moderate" ventilation case, particularly in cases when there is the occurrence of the "interface breakdown".

Water flow velocity at $9.6 \mathrm{~m}$ station

In general, the results obtained with the proposed numerical model are comparable with the experiments, particularly the ability of the model to describe the bore arrival, the "pre-bore motion" feature and the subsequent oscillations in velocity due to the motion in the surge tank. Yet, as Figure 19.10 shows, the predictions for the cases when the initial water depth is smaller are worse than the ones with higher initial depth. This is noticeable because of velocity oscillations that are predicted after the bore reaches the riser, which are not observed in the experiments. The two cases in which this happens are, however, the exact two cases when the numerical model predicts the occurrence of IBD, which is also observed in the experimental runs. Because the model is single-phase, when the bore reaches the riser and causes the entrapment of the air pocket, it cannot adequately simulate the system behavior. As a result, model predictions are compromised whenever the numeric model predicts the occurrence of IBD features.

Water pressure at $9.6 \mathrm{~m}$ station

Similarly as described previously, the model is able to simulate the passage of the pressurization bore through the $9.6 \mathrm{~m}$ station with a good degree of accuracy. 
In Figure 19.11, one may notice that the increase in the pressure prior to the bore arrival at the surge tank is in most cases more than twice the correspondent ones for the "Moderate" ventilation case. The problems start when the bore reaches the surge tank and high-frequency numerical oscillations begin to appear, for the same reasons as explained in the case of "Moderate" ventilation. These oscillations are much worse in the cases when the IBD occurs, and even after "averaging" the results are not reasonable.

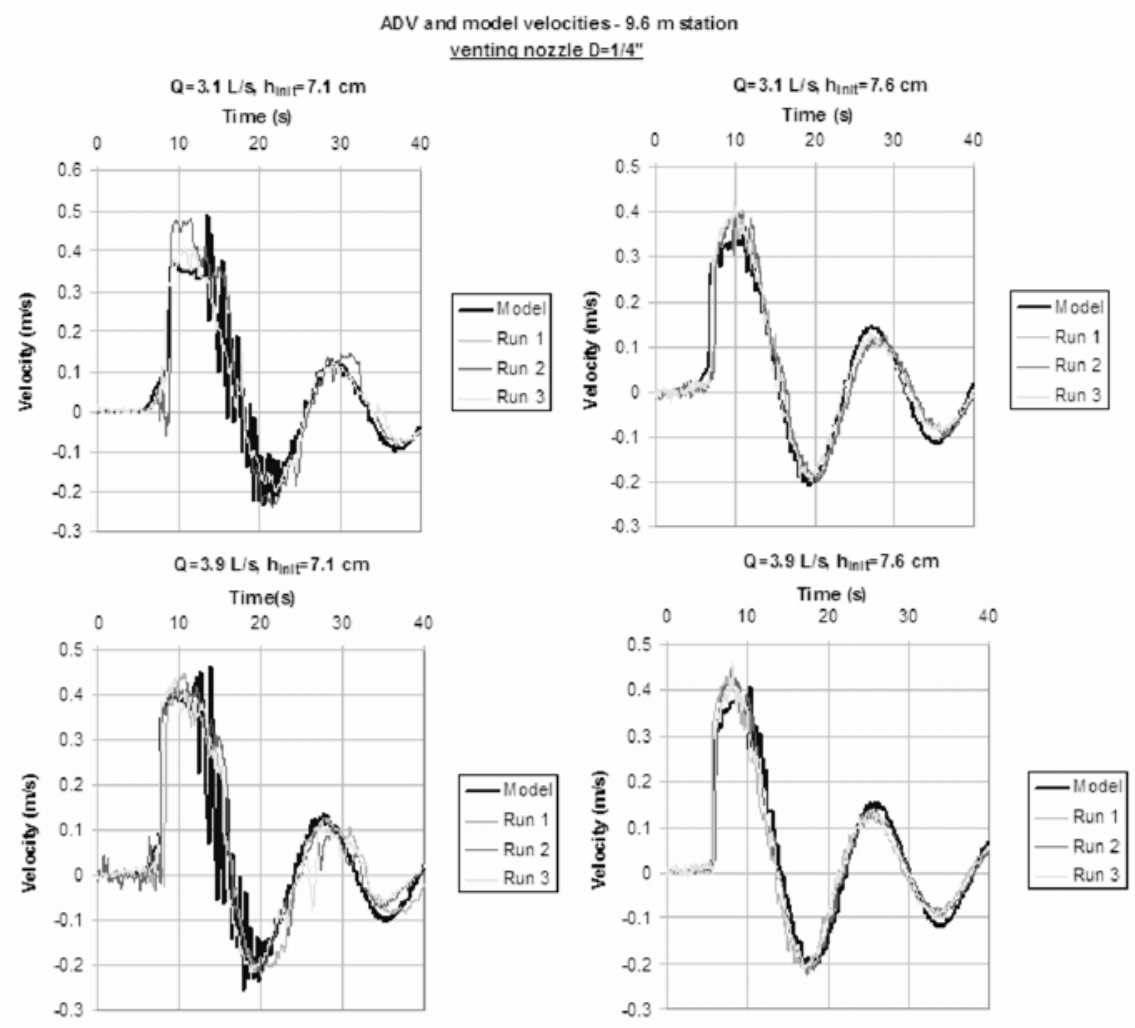

Figure 19.10 Comparison of velocity at the $9.6 \mathrm{~m}$ between proposed model and the experimental runs - "Poor" ventilation case

Air pressure at $14.1 \mathrm{~m}$ station

Again, the predicted results for the air phase pressure increase are reasonably well modeled in the "Poor" ventilation case when compared to the 
experimental data. As Figure 19.12 shows, the air phase pressure is more than two times higher than the case when the $3 / 8$ inch $(10 \mathrm{~mm})$ venting nozzle is used, with higher pressures for lower initial depths and higher inflow rates. The problems with the numerical oscillations on the predicted air pressures are now more noticeable, with the numerical oscillations in the order of $10 \%$ of the actual pressure. The results in general are slightly better for smaller inflow rates.

Water pressure at $14.1 \mathrm{~m}$ station

The observations made for the $9.6 \mathrm{~m}$ station pressure predictions can be extended to the predictions for the $14.1 \mathrm{~m}$ station, displayed in Figure 19.13. In brief, the predicted pressures match the observations during the phase when the bore travels in the pipeline, but there are problems as soon as the bore arrives at the surge tank..
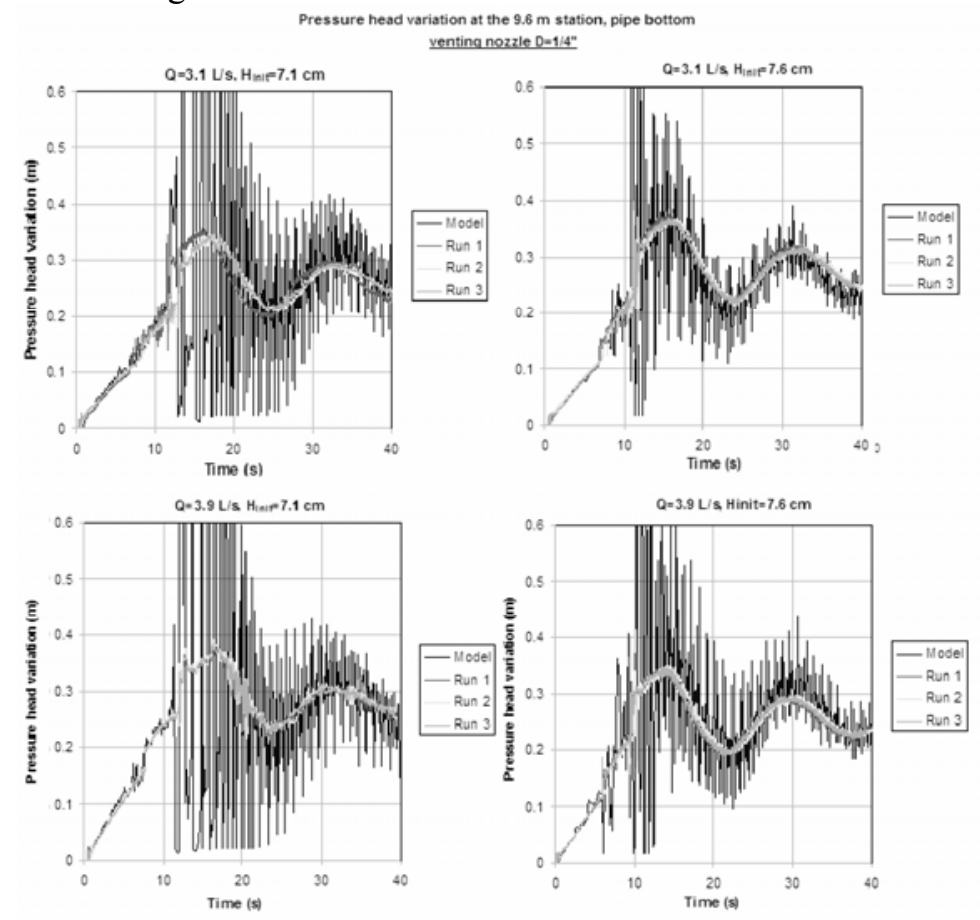

Figure 19.11 Comparison of water phase pressure head variation at the $9.6 \mathrm{~m}$ between proposed model and the experimental runs - "Poor" ventilation case 
In the two cases when there is the occurrence of the IBD, the results are worse, and even after so-called averaging between the numerical oscillations the results are not comparable to the experimental observations
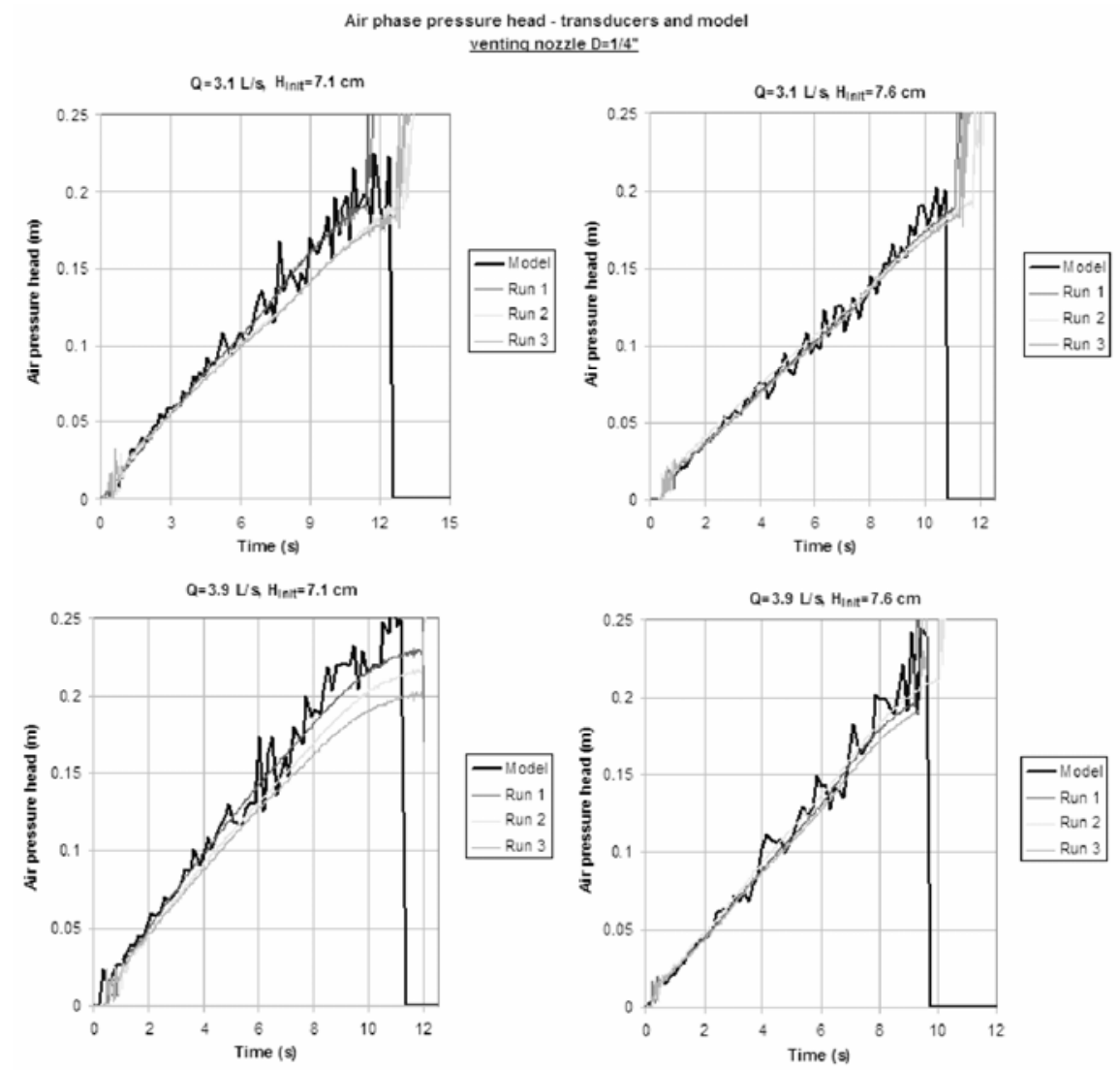

Figure 19.12 Comparison of air phase pressure head between proposed model and the experimental runs - "Poor" ventilation case

\section{Depth at 14.1 m station}

The predicted depth changes in the models are reasonably well described by the numeric model, as Figure 19.14 shows. The depth variations are larger than the correspondent ones for the "Moderate" ventilation case, and can be as much as $15 \%$ of the original depth. The model was able to capture the general 
behavior of the depth changes, including the "pre-bore motion" and the arrival of the pressurization bore. In the cases when the initial water depth is larger, the model over-predicts the depth changes for times after 6 seconds, and this is probably related to the interaction between the "pre-bore motion" and the pressurization bore.
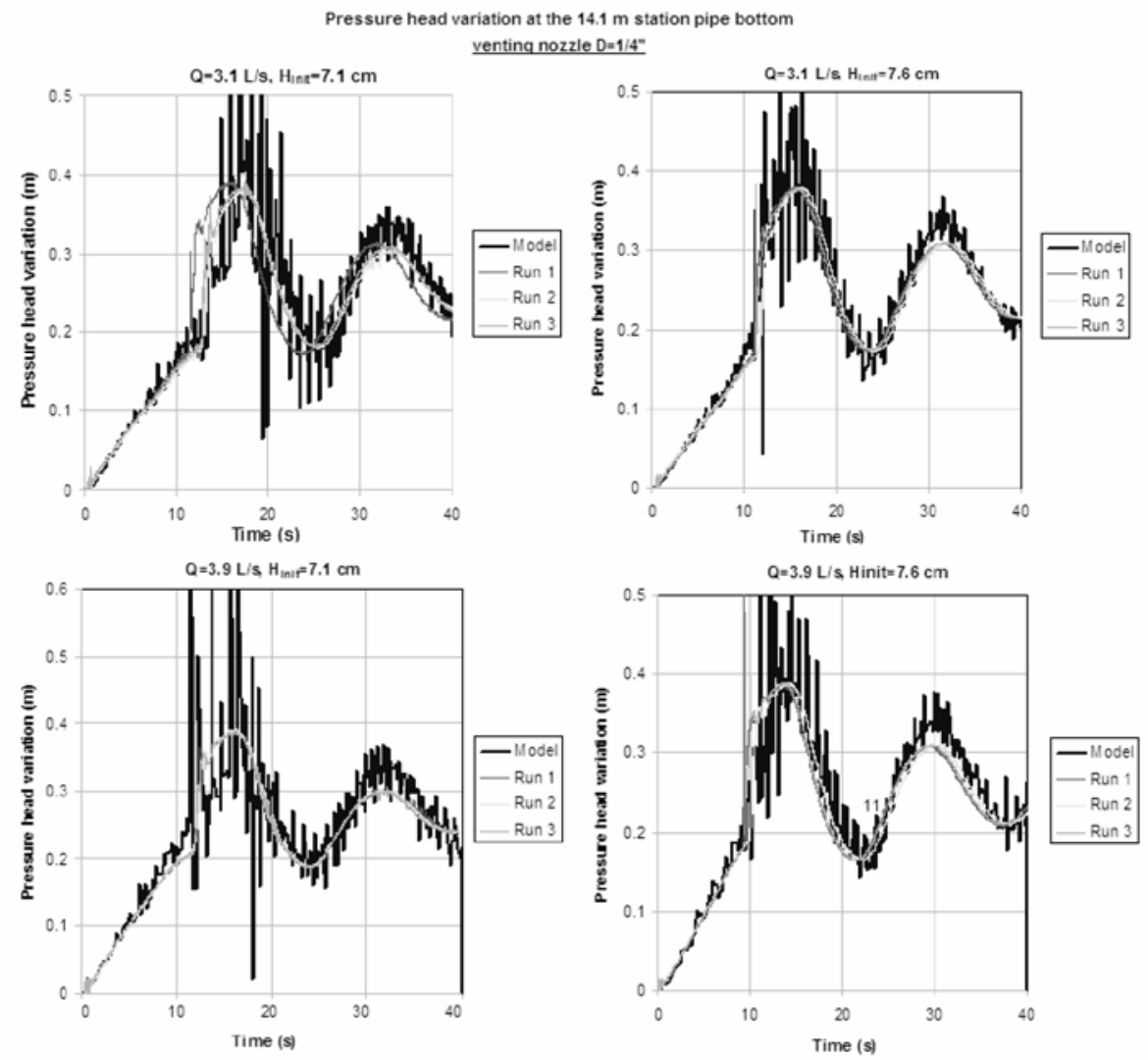

Figure 19.13 Water phase pressure head variation at $14.1 \mathrm{~m}$ between proposed model and the experimental runs - "Poor" ventilation case

\subsubsection{Numerical prediction of "interface breakdown" occurrence}

The objective of this section is to illustrate the prediction of the "interface breakdown" feature by the numerical model. This is an improvement 
compared to the model presented in Vasconcelos and Wright (2004b), because this signals when the results of a single-phase model approach would be compromised by the occurrence of an entrapped air pocket. Some of the other problems observed with the predicted results, such as the high frequency pressure oscillations, are not so important since in average they wouldn't affect the system behavior significantly. On the other hand, it was shown that the predicted results are much worse in the cases when the IBD develops, and in those cases a two-phase numerical model would be required to include the air pocket in the model appropriately.

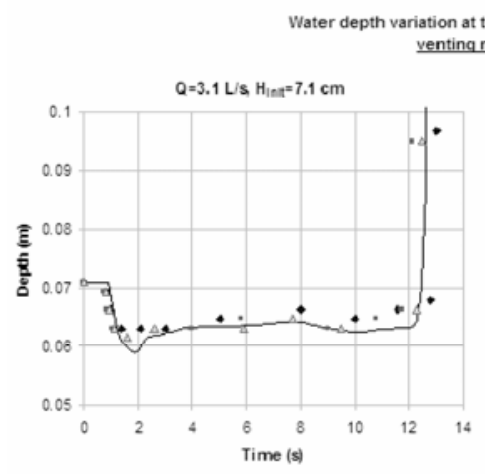
$\mathrm{m}$ station pipe bottom enting nozzle $D=1 / 4^{\prime \prime}$ - Run 1 - Run $2 \Delta$ Run 3 - Model
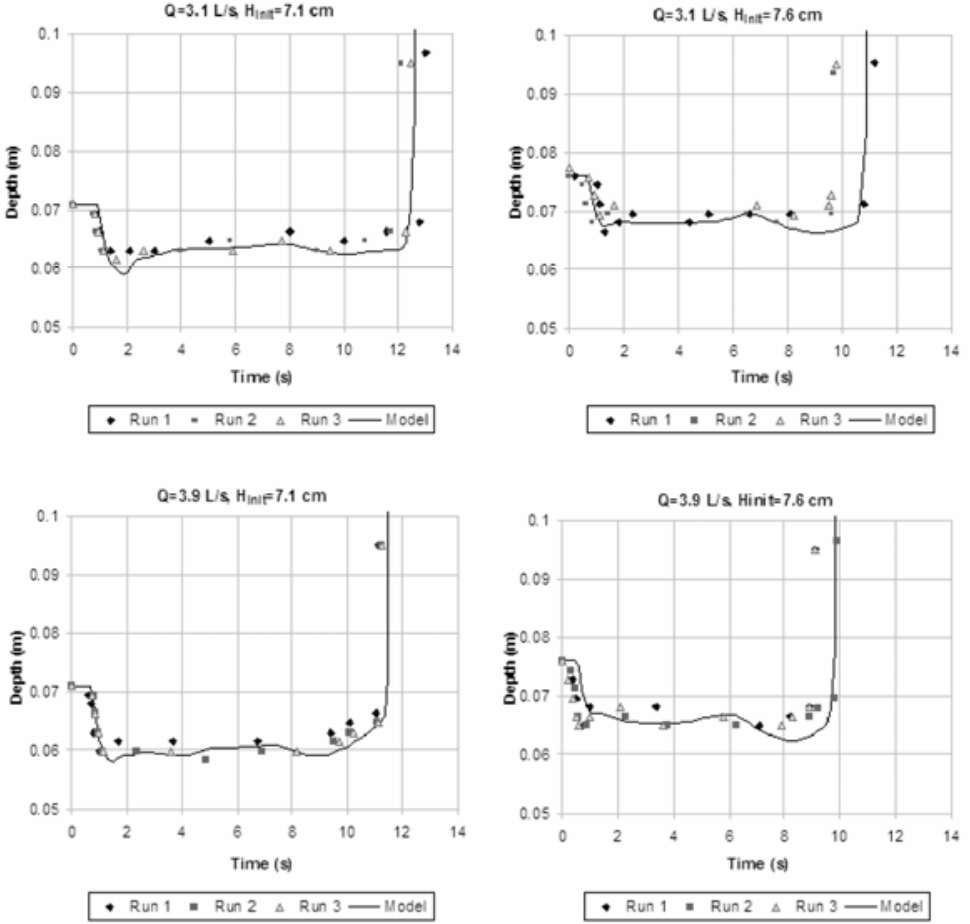

Figure 19.14 Comparison of water depth variation at the $14.1 \mathrm{~m}$ between proposed model and the experimental runs - "Poor" ventilation case 
Figure 19.15 shows four snapshots of the predicted velocity and depth profiles along the pipeline for the case when $Q=3.1 \mathrm{~L} / \mathrm{s}, H_{\text {init }}=7.1 \mathrm{~cm}$ and $D_{\text {orif }}=1 / 4$ inch. The first snapshot, at $T=4.0$ seconds, illustrates the pipe-filling bore advancing towards the surge tank and the "pre-bore motion" feature moving towards the upstream end. Those two flow features will eventually meet, and that happens according to the model at 8.0 seconds. Shortly after this another snapshot is taken $(T=8.2 \mathrm{~s})$, and the onset of the intrusion in the top of the pressurization bore can be seen. While the model predicts the formation of the intrusion at $9 \mathrm{~m}$, experimental observations indicates that this occurs at $9.3 \mathrm{~m}$, which is reasonably close. After the IBD occurrence, there are some pressure fluctuations, which are transmitted in the pressurized zone, causing the pressure drop observed at $T=8.2 \mathrm{~s}, x=4.5 \mathrm{~m}$.
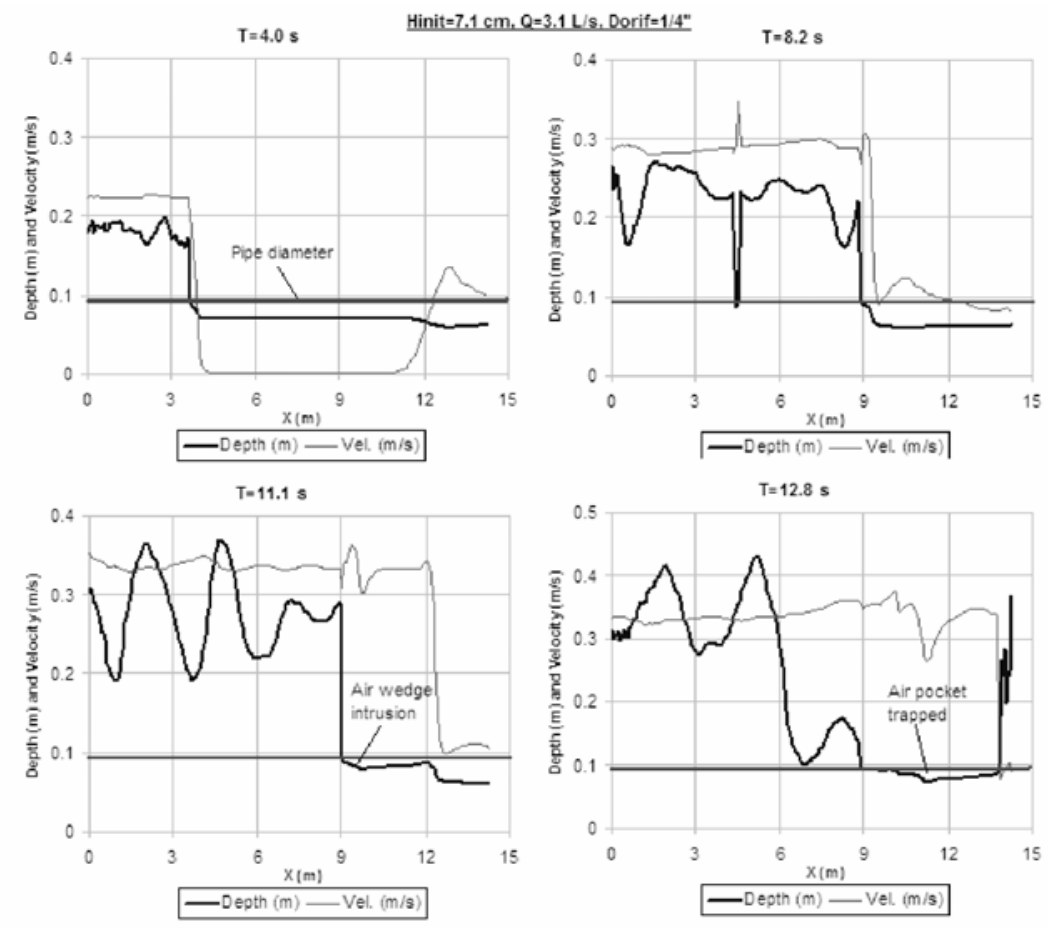

Figure 19.15 Four snapshots of depth and velocity profiles in the tunnel showing the numerical prediction of the IBD occurrence 
The air pocket continues to grow as the bore continues to advances, and this is illustrated in the snapshot taken at $T=11.1 \mathrm{~s}$. Eventually the bore arrives at the surge tank, as shown for $T=12.8 \mathrm{~s}$, and the system has an entrapped air pocket, which cannot be properly dealt in this single-phase model.

\subsection{Summary and Conclusions}

Intense rain events may cause changes in the operational conditions of stormwater drainage systems, causing the occurrence of flow regime transition between the free-surface and pressurized flow. This problem can be classified as a rapid filling pipe problem, and there are a number of different model approaches that can be used, some of them including the effect of the air phase pressure in the model calculations. Most of these models are based in single-phase flow approaches and the incorporation of the air phase effects is promoted by including some simplifications in the description of the air phase behavior. Although there are one-dimensional, two-phase flow models constructed around mass and momentum equations for both phases, it is not clear that these models would be able to describe the rapid filling pipe of quasi-horizontal conduits.

To date, no study has been promoted to determine the limits of applicability of single-phase models to the description of the rapid filling pipe problems. Clearly, those limits are related to the entrapment of air pockets. In the cases when there is a single layer of air ahead of the pressurization bore the modeling of the air phase can be greatly simplified with some key assumptions. These simplifications reduce the partial differential equations required in the description of the air phase into simple algebraic relations that can be used to simulate the air phase pressure, density and velocity along the domain. However, those assumptions aren't valid in cases when there are air pockets, and appropriate treatment of those is required for modeling purposes. This may include, for instance, the use of two-phase flow approaches.

The proposed model has several advantages over the one presented by Vasconcelos and Wright (2004b). First, it is able to describe the propagation of the pressurization bore with minimal numerical diffusion or oscillations across the pressurization front. Second, it can handle more limited venting conditions, which in turn allow the prediction of the "pre-bore motion" feature and the occurrence of "interface breakdown". And finally, by 
predicting the IBD, the model indicates when its applicability would be compromised by the formation of air pockets.

There are some improvements still required to this model. First, the high frequency oscillations in pressure predictions observed as the bore reaches the surge tank should be eliminated. One way to achieve this may be by switching the model approach (using for instance the Method of Characteristics) as soon as the system is completely filled with water. Second, it is possible that a model with higher order of accuracy to describe the advance of the pressurization bore could improve the predictions. Third, the predictions may be improved by applying a two-phase model approach as soon as there is the formation of a pipe-filling bore, as long no air pockets are present. Finally, if this model aims to describe the rapid filling of storm systems, them it should include the effects of air pockets that eventually may be trapped within the system. All those possibilities are currently being considered in the future work related to this research.

\section{Acknowledgments}

The authors would like to acknowledge the support of the CNPq, a Brazilian Government entity committed to the development of science and technology, which has provided a fellowship to support the $\mathrm{PhD}$. studies of the first author.

Also the authors would like to thank Prof. Ben Wylie and Prof. Phil Roe for the fruitful discussions related to the model alternatives available to solve this problem.

\section{References}

Arai, K. and Yamamoto, K. (2003). "Transient analysis of mixed free-surface-pressurized flows with modified slot model - part1: Computational model and experiment." Proc. FEDSM03 - 4th ASME-JSME Joint Fluids Engrg. Conference, Honolulu, HW. ASME/JSME.

Barnea, D. and Taitel, Y. (1993). "Model for slug length distribution in gas-liquid slug flow.” Int. J. Multiphase Flow, 19(5), 829-838.

Cabrera, E., Abreu, J., Perez, R., and Vela, A. (1990). "Influence of liquid length variation in hydraulic transients." J. Hydr. Engrg., 118(12), 1639-1650.

Capart, H., Sillen, X., and Zech, Y. (1997). "Numerical and experimental water transients in sewer pipes.” J. Hydr. Res., 35(5), 659-670. 
Cardle, J. A. and Song, C. S. S. (1988). "Mathematical modeling of unsteady flow in storm sewers.” Int. J. Engrg. Fluid Mech., 1(4), 495-518.

Cunge, J. A., Jr., F. M. H., and Verwey, A. (1980). Practical Aspects of Computational River Hydraulics. Pitman Publishing Ltd., London, UK.

DeHenau, V. and Raithby, G. D. (1995). "Transient two-fluid model for the simulation of slug flow in pipelines.” Int. J. Multiphase Flow, 21(3), 335-349.

Garcia-Navarro, P., Priestley, A., and Alcrudo, F. (1994). "Implicit method for water flow modeling in channels and pipes." J. Hydr. Res., 32(5), 721-742.

Glaister, P. (1988). "Approximate Riemann solutions of the shallow water equations.” J. Hydr. Res., 26(3), 293-306.

Guo, Q. and Song, C. S. S. (1990). "Surging in urban storm drainage systems.” J. Hydr. Engrg., 116(12), 1523-1537.

Guo, Q. and Song, C. S. S. (1991). "Dropshaft hydrodynamics under transient conditions." J. Hydr. Engrg., 117(8), 1042-1055.

Hamam, M. A. and McCorquodale, J. A. (1982). "Modeling mixed flow in storm sewers." Ca. J. Civ. Engrg., (9), 189-196.

Issa, R. I. and Kempf, M. H. W. (2003). "Simulation of slug flow in horizontal and nearly horizontal pipes with the two-fluid model.” Int. J. Multiphase Flow,29(1), 69-95.

Li, J. and McCorquodale, A. (1999). "Modeling mixed flow in storm sewers." J. Hydr. Engrg., 125(11), 1170-1180.

Macchione, F. and Morelli, M. A. (2003). "Practical aspects in comparing the shockcapturing schemes for dam break problems." J. Hydr. Engrg., 129(3), 187-195.

Martin, C. S. (1976). "Entrapped air in pipelines.” Proc. 2nd Int. Conf. Pressure Surges, BHRA, ed., Bedford, England.

Nguyen, T. D. (1999). "Numerical simulation of the flow in a conduit in the presence of a confined air cushion.” Int. J. Num. Meth. in Fluids, 29(4), 485-498.

Roe, P. L. (1981). "Approximate Riemann solvers, parameter vectors, and difference schemes." J. Comp. Physics, 43, 357-372.

Song, C. S. S., Cardle, J. A., and Leung, K. S. (1983). "Transient mixed-flow models for storm sewers.” J. Hydr. Engrg., 109(11), 1487-1504.

Vasconcelos, J. G. and Wright, S. J. (2004a). "Experimental investigation of large surges generated in stormwater storage tunnels with restricted venting conditions. Submitted to the Journal of Hydraulic Engineering.

Vasconcelos, J. and S.J. Wright. 2004b. "Numerical Modeling of the Transition between Free Surface and Pressurized Flow in Storm Sewers." Journal of Water Management Modeling R220-10. doi: 10.14796/JWMM.R220-10.

Wiggert, D. C. (1972). "Transient flow in free-surface, pressurized systems.” J. Hydr. Div., 98(HY1), 11-27.

Wright, S.J., J. Vasconcelos and K. Ridgway. 2003. "Surges Associated with Filling of Stormwater Storage Tunnels." Journal of Water Management Modeling R215-18. doi: 10.14796/JWMM.R215-18.

Wylie, E. B. and Streeter, V. L. (1993). Fluid Transients in Systems. Prentice Hall, Upper Saddle River, NJ.

Zhou, F, Hicks, F. E., and Stefler, P. M. (2002). "Transient flow in a rapidly filling horizontal pipe containing trapped air.” J. Hydr. Engrg., 128(6), 625-634. 
